\title{
CYP1A1 Mspl polymorphism and acute myeloid leukemia risk: meta-analyses based on 5018 subjects
}

Wenlei Zhuo ${ }^{*}$, Liang Zhang ${ }^{2}$, Yan Wang ${ }^{3}$, Bo Zhu ${ }^{1}$ and Zhengtang Chen ${ }^{1}$

\begin{abstract}
Background: Evidence indicates that CYP1A1 Mspl polymorphism might be a possible risk factor for several malignancies. A growing body of literature has been devoted to the association of CYP1A1 Mspl polymorphism with acute myeloid leukemia (AML). However, the results remain conflicting. The aim of the present study was to derive a more precise estimation of the relationship.

Methods: Meta-analyses assessing the association of CYP1A1 Mspl variation with AML were conducted and subgroup analyses on ethnicity and age groups were further performed. Eligible studies were identified for the period up to May 2012.

Results: A total of ten case-control studies including 1330 cases and 3688 controls were selected for analysis. The overall data failed to indicate a significant association of CYP1A1 Mspl polymorphism with AML risk (C vs T: $\mathrm{OR}=1.13 ; 95 \% \mathrm{Cl}=0.87-1.48 ; \mathrm{CC}$ vs $T \mathrm{~T}: \mathrm{OR}=1.72 ; 95 \% \mathrm{Cl}=0.99-3.01 ; \mathrm{CC}+\mathrm{TC}$ vs $T \mathrm{~T}: \mathrm{OR}=1.16 ; 95 \% \mathrm{Cl}=0.86-1.55) . \mathrm{In}$ subgroup analysis stratified by ethnicity, significant AML risk was shown among Asians (CC + TC vs TT: OR=1.33; $95 \% \mathrm{Cl}=1.09-1.62$ ) but not Caucasians or mixed races. In subgroup analysis regarding age groups, no associations were observed in either the childhood AML or the adult AML subgroups.
\end{abstract}

Conclusion: The results of the present study suggested that CYP1A1 Mspl polymorphism might be a risk factor for AML among Asians. Further investigations are needed to confirm the conclusions.

Keywords: CYP1A1 Mspl, Acute myeloid leukemia, Malignancy, Susceptibility, Meta-analysis, Polymorphism

\section{Introduction}

Acute myeloid leukemia (AML), also known as acute nonlymphocytic leukemia (ANLL), is the most common acute leukemia mostly affecting adults, characterized by the rapid growth of abnormal white blood cells in the bone marrow and impaired production of normal blood cells. The mechanisms for AML genesis are still rarely understood. Evidence suggests that radiation, smoking, obesity and exposure to chemical carcinogens are considered as its possible risk factors [1]. Nevertheless, AML only develops in a small proportion of people exposed to these environmental and lifestyle risk factors,

\footnotetext{
* Correspondence: zhuowenlei@yahoo.com.cn

${ }^{1}$ Institute of Cancer, Xinqiao Hospital, Third Military Medical University, Chongqing, China

Full list of author information is available at the end of the article
}

indicating that the host genetic background might play a critical role in its genesis.

Several genetic polymorphisms have been determined as possible risk factors for leukemia by meta-analyses. Variations of GSTM1, GSTT1, MTHFR C677T and XRCC1 Arg399Gln have been indicated to raise leukemia susceptibility [2-4]. Nevertheless, polymorphic MTR A2756G has been shown to decrease acute leukemia risk [5]. Therefore, different genetic polymorphisms might exert different effects on leukemia risk. Nevertheless, only a few gene polymorphisms associated with leukemia susceptibility have been identified to date.

Recent evidence indicates that carcinogen-metabolizing genes might play critical roles in determining individual susceptibility to cancers [6]. Susceptibility to cancer is determined by the activation of enzymes involved in carcinogen activation or deactivation. Polymorphisms in

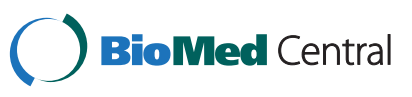


these genes encoding the enzymes, possibly by altering their functions, might increase or decrease carcinogen activation/detoxification and modulate DNA repair process. Cytochrome P450 (CYP) enzymes catalyze Phase I metabolism reaction. Cytochrome P450 1A1 (CYP1A1) is a member of the CYP family that participates in the metabolism of xenobiotics and endogenous compounds, particularly polycyclic aromatic hydrocarbons (PAHs) such as benzo[a]pyrene in smoke [7]. A commonly studied single nucleotide polymorphism (SNP) in the CYP1A1 gene has been indicated to associate with cancer susceptibility. The SNP locates at nucleotide 3801 in the 3' non-coding region containing a single $\mathrm{T}$ to $\mathrm{C}$ base substitution that results in a polymorphic restriction site for the MspI enzyme (MspI or CYP1A1*2A polymorphism, rs4646903). The MspI restriction site polymorphism results in three genotypes: a predominant homozygous $\mathrm{m} 1$ allele without the MspI site (type A, TT), the heterozygote (type B, TC) and a homozygous rare $\mathrm{m} 2$ allele with the MspI site (type $\mathrm{C}$, CC) [8].

Published studies devoted to the relationship between CYP1A1 MspI polymorphism and AML risk have generated controversial results. The issue of whether CYP1A1 MspI polymorphism is a risk factor for AML remains uncertain. Therefore, in this study, we aimed to perform a quantitative meta-analysis that increased statistical power to generate more confidential results.

\section{Materials and methods}

\section{Literature search strategy}

We carried out a search in the Medline, EMBASE, OVID, Sciencedirect, and Chinese National Knowledge Infrastructure (CNKI) without a language limitation, covering all publications published up to May 2012, with a combination of the following keywords: Cytochrome P450 1A1, CYP1A1, T3801C, MspI, acute myeloid leukemia, acute nonlymphocytic leukemia, hematology, malignancy, neoplasm, cancer, variation and polymorphism. All searched studies were retrieved and the bibliographies were checked for other relevant publications. Review articles and bibliographies of other relevant studies identified were hand searched to find additional eligible studies.

\section{Inclusion and exclusion criteria}

The following criteria were used for the literature selection: first, studies should concern the association of CYP1A1 MspI polymorphism with AML risk; second, studies must be observational studies (Case-control or cohort); third, papers must offer the size of the sample, odds ratios (ORs) and their 95\% confidence intervals (CIs), the genetic distribution or the information that can help infer the results. Accordingly, the following criteria for exclusion were also utilized: first, the design and the definition of the experiments were obviously different from those of the selected articles; second, the

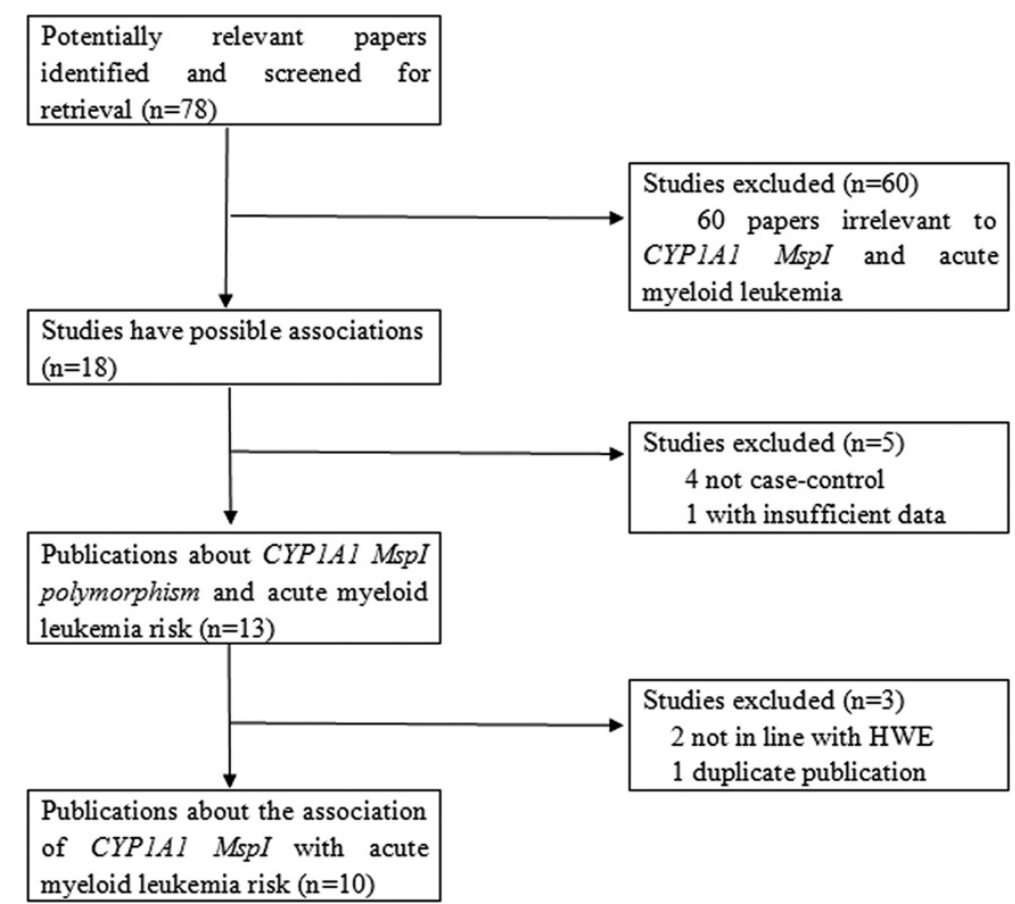

Figure 1 The flow diagram of included/excluded studies. 
Table 1 Characteristics of studies included in the meta-analysis

\begin{tabular}{|c|c|c|c|c|c|c|c|c|}
\hline First Author & $\begin{array}{c}\text { Publication } \\
\text { Year }\end{array}$ & $\begin{array}{c}\text { Number of Leukemia } \\
\text { Cases (male/female) }\end{array}$ & $\begin{array}{c}\text { Number of Controls } \\
\text { (male/female) }\end{array}$ & $\begin{array}{l}\text { Number of } \\
\text { AML cases }\end{array}$ & Type of controls & $\begin{array}{c}\text { Median (or mean) age, } \\
\text { (range) year (Cases/Controls) }\end{array}$ & $\begin{array}{l}\text { Racial } \\
\text { decent }\end{array}$ & Country \\
\hline Balta & 2003 & $33(19 / 14)$ & $185(120 / 65)$ & $33 \mathrm{AML}$ & Healthy controls (PB) & $8.7(1-17) / 7.4(0.58-17)$ & Mixed & Turkey \\
\hline D'Alo & 2004 & $193(107 / 86)$ & $273(147 / 126)$ & $193 \mathrm{AML}$ & Healthy controls (PB) & $62(19-87) / 60(19-90)$ & Caucasian & Italy \\
\hline Clavel & 2005 & $219(129 / 90)$ & $105(57 / 48)$ & $28 \mathrm{AML}$ & $\begin{array}{l}\text { Non-cancer controls } \\
\text { (age,- gender-, hospital-, } \\
\text { ethnicity-matched; HB) }\end{array}$ & $\mathrm{NA}(0-15) / \mathrm{NA}(0-15)$ & Mixed & France \\
\hline Aydin-Sayitoglu & 2006 & $249(143 / 106)$ & $140(73 / 67)$ & $\begin{array}{l}50 \text { adult } A M L ; \\
44 \text { pediatric } A M L\end{array}$ & Healthy controls (PB) & $\begin{array}{l}\text { Adult:33(19-75); pediatric: } \\
\text { 7.8(2-18)/28.7(16-59) }\end{array}$ & Caucasian & Turkey \\
\hline Bolufer & 2007 & $443(223 / 190)$ & $454(223 / 231)$ & $302 \mathrm{AML}$ & Healthy controls (PB) & $39.48(0.8-84) / 38.38(1-85)$ & Caucasian & Spain \\
\hline Jiang & 2008 & 98 (NA) & $120(\mathrm{NA})$ & $98 \mathrm{AML}$ & $\begin{array}{l}\text { Healthy controls } \\
\text { (age-, sex-matched; PB) }\end{array}$ & NA(16-68)/NA(16-68) & Asian & China \\
\hline Majumdar & 2008 & $110(70 / 40)$ & $126(54 / 72)$ & $110 \mathrm{AML}$ & Healthy controls (PB) & $35(4-81) / 30(8-73)$ & Asian & India \\
\hline Yamaguti & 2009 & $133(70 / 63)$ & $133(70 / 63)$ & $133 \mathrm{AML}$ & Healthy controls (PB) & $47(11-89) / 53(25-60)$ & Mixed & Brazil \\
\hline Bonaventure & 2012 & $493(266 / 227)$ & $549(292 / 257)$ & $51 \mathrm{AML}$ & $\begin{array}{c}\text { Healthy controls } \\
\text { (age-, gender-matched; PB) }\end{array}$ & $\mathrm{NA}(0-15) / \mathrm{NA}(0-15)$ & Caucasian & France \\
\hline Kim & 2012 & $415(223 / 192)$ & $1700(821 / 879)$ & $415 \mathrm{AML}$ & Healthy controls (PB) & $50.5(15-86) / 52.2(20-74)$ & Asian & Korea \\
\hline
\end{tabular}


source of cases and controls and other essential information were not offered; third, reviews and duplicated publications. After deliberate searching, we reviewed all papers in accordance with the criteria defined above for further analysis.

\section{Data extraction}

Data were carefully extracted from all eligible publications independently by two of the authors according to the inclusion criteria mentioned above. For conflicting evaluations, an agreement was reached following a discussion. If a consensus could not be reached, another author was consulted to resolve the dispute and then a final decision was made by the majority of the votes. The extracted information was entered into a database.

\section{Statistical analysis}

The odds ratio (OR) of CYP1A1 MspI polymorphisms and AML risk was estimated for each study. The pooled ORs were performed for an allelic contrast ( $\mathrm{C}$ allele versus $\mathrm{T}$ allele), a homozygote comparison (CC versus $\mathrm{TT}$ ) and a dominant model $(\mathrm{CC}+\mathrm{TC}$ versus $\mathrm{TT})$. For detection of any possible sample size biases, the OR and its 95\% confidence interval (CI) to each study was plotted against the number of participants respectively. A Chisquare based $\mathrm{Q}$ statistic test was performed to assess heterogeneity. If the result of the Q-test was $P>0.1$, ORs were pooled according to the fixed-effect model (Mantel-Haenszel); otherwise, the random-effect model (DerSimonian and laird) was used. The significance of the pooled ORs was determined by Z-test. The HardyWeinberg equilibrium (HWE) was assessed by Fisher's exact test. Publication bias was assessed by visual inspection of funnel plots [9], in which the standard error of $\log (\mathrm{OR})$ of each study was plotted against its log (OR). An asymmetric plot indicates a possible publication bias. The symmetry of the funnel plot was further evaluated by Egger's linear regression test [10]. Statistical analysis was undertaken using the program STATA 11.0 software (Stata Corporation, Texas).

\section{Results}

\section{Study characteristics}

Relevant publications were retrieved and screened originally. A total of seventy-eight publications were identified, of which sixty irrelevant papers were excluded. As shown in Figure 1, eighteen publications were preliminary eligible, of which four publications not being casecontrol studies [11-14] and one article not presenting sufficient information [15] were discarded. Next, two studies $[16,17]$ whose genetic distributions of the control groups exhibited evident deviation from HWE were excluded. Then, one duplicate publication [18] which concerned the same research with one of the included studies [19] was further excluded. Lastly, ten casecontrol studies were selected for data extraction [19-28].

Of the selected publications, one was written in Chinese [24] while the remaining nine were in English. The relevant information was listed in Table 1. According to this table, the first author and the number and characteristics of cases and controls for each study as well as other necessary information are presented.

There were four groups of Caucasians [19,21,25,26], three of Asians [20,23,24] and three of mixed races $[22,27,28]$ in this meta-analysis. As for age groups, there were seven groups of adult AML [19,20,22-26] and four groups of childhood AML $[21,25,27,28]$ in this study. Noticeably, the study conducted by Aydin-Sayitoglu et al... [25] involved two subgroups regarding adult AML and childhood AML, respectively.

The distributions of CYP1A1 MspI genotype as well as the genotyping methods of the included studies are presented in Table 2. The genetic distributions of the

Table 2 Distribution of CYP1A1 Mspl genotypes among acute myeloid leukemia cases and controls included in the meta-analysis

\begin{tabular}{|c|c|c|c|c|c|c|c|c|c|c|}
\hline \multirow[t]{2}{*}{ First Author } & \multirow[t]{2}{*}{ Year } & \multirow[t]{2}{*}{ Genotyping method } & \multicolumn{3}{|c|}{ Cases } & \multicolumn{3}{|c|}{ Controls } & \multicolumn{2}{|c|}{ HWE (control) } \\
\hline & & & $\mathrm{CC}$ & TC & $\mathrm{TT}$ & $\mathrm{CC}$ & TC & $\mathrm{TT}$ & Chi-squre & $\mathbf{P}$ \\
\hline Balta & 2003 & PCR-RFLP & 0 & 6 & 20 & 7 & 35 & 103 & 2.862 & $>0.05$ \\
\hline D'Alo & 2004 & PCR-RFLP & 0 & 17 & 161 & 0 & 42 & 226 & 1.937 & $>0.05$ \\
\hline Clavel & 2005 & PCR-RFLP & 0 & 5 & 22 & 0 & 24 & 81 & 1.748 & $>0.05$ \\
\hline Aydin-Sayitoglu & 2006 & PCR-RFLP & 5 & 24 & 65 & 4 & 30 & 106 & 1.049 & $>0.05$ \\
\hline Bolufer & 2007 & Real-time PCR & 0 & 31 & 168 & 2 & 84 & 317 & 2.062 & $>0.05$ \\
\hline Jiang & 2008 & PCR-RFLP & 19 & 50 & 29 & 26 & 50 & 44 & 2.610 & $>0.05$ \\
\hline Majumdar & 2008 & PCR-RFLP & 30 & 39 & 41 & 9 & 51 & 66 & 0.040 & $>0.05$ \\
\hline Yamaguti & 2009 & PCR-RFLP & 9 & 59 & 65 & 6 & 32 & 95 & 2.199 & $>0.05$ \\
\hline Bonaventure & 2012 & Infinium platform & 2 & 7 & 41 & 7 & 87 & 454 & 1.435 & $>0.05$ \\
\hline Kim & 2012 & PCR-RFLP & 61 & 219 & 135 & 263 & 801 & 636 & 0.170 & $>0.05$ \\
\hline
\end{tabular}


Table 3 Main results of the pooled data in the meta-analysis

\begin{tabular}{|c|c|c|c|c|c|c|c|c|c|c|}
\hline \multirow[t]{3}{*}{ 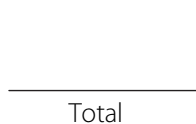 } & \multirow[t]{2}{*}{ No. (cases/controls) } & \multicolumn{3}{|c|}{ C allele vs T allele } & \multicolumn{3}{|c|}{ CC vs TT } & \multicolumn{3}{|c|}{$(\mathrm{CC}+\mathrm{TC})$ vs TT } \\
\hline & & OR $(95 \% \mathrm{Cl})$ & $P(O R)$ & P (Q-test) & OR $(95 \% \mathrm{Cl})$ & $P(O R)$ & $\mathrm{P}$ (Q-test) & OR $(95 \% \mathrm{Cl})$ & $P(O R)$ & $\mathrm{P}$ (Q-test) \\
\hline & $1330 / 3688$ & $1.13(0.87-.1 .48)$ & 0.349 & 0.000 & $1.72(0.99-3.01)$ & 0.055 & 0.026 & $1.16(0.86-1.55)$ & 0.326 & 0.002 \\
\hline \multicolumn{11}{|l|}{ Ethnicity } \\
\hline Caucasian & $521 / 1359$ & $0.90(0.59-.1 .37)$ & 0.629 & 0.062 & $2.02(0.76-5.36)$ & 0.160 & 0.462 & $0.85(0.57-1.26)$ & 0.415 & 0.127 \\
\hline Asian & $623 / 1946$ & $1.35(0.90-2.02)$ & 0.150 & 0.004 & $1.77(0.72-4.35)$ & 0.214 & 0.002 & $1.33(1.09-1.62)$ & 0.004 & 0.382 \\
\hline Mixed & $186 / 383$ & $1.11(0.48-2.55)$ & 0.807 & 0.029 & $1.40(0.28-6.90)$ & 0.681 & 0.227 & $1.24(0.48-3.22)$ & 0.654 & 0.021 \\
\hline \multicolumn{11}{|l|}{ Age groups } \\
\hline Adult AML & $1183 / 2890$ & $1.21(0.88-1.66)$ & 0.244 & 0.000 & $1.76(0.94-3.30)$ & 0.078 & 0.015 & $1.26(0.88-1.81)$ & 0.213 & 0.000 \\
\hline Childhood AML & $147 / 938$ & $1.02(0.69-1.49)$ & 0.938 & 0.620 & $1.78(0.60-5.32)$ & 0.299 & 0.376 & $0.97(0.63-1.49)$ & 0.877 & 0.856 \\
\hline
\end{tabular}

$\mathrm{AML}$, acute myeloid leukemia.

control groups in all included studies were consistent with HWE.

\section{Test of heterogeneity}

As shown in Table 3, we analyzed the heterogeneity for the allelic contrast ( $\mathrm{C}$ allele versus $\mathrm{T}$ allele), homozygote comparison ( $\mathrm{CC}$ versus $\mathrm{TT})$ and dominant model $(\mathrm{CC}+$ $\mathrm{TC}$ versus $\mathrm{TT}$ ), respectively. Evident heterogeneities were observed for the overall data in the three genetic comparisons $(C$ allele versus $T$ allele: $P=0.000$ for Q-test; $C C$ versus TT: P $=0.026$ for Q-test; $C C+$ TC versus TT: $\mathrm{P}=0.002$ for $\mathrm{Q}$-test). Additionally, $I$-square value is another index for the heterogeneity test [29], with value less than $25 \%$ indicating low, $25 \%$ to $50 \%$ indicating moderate, and greater than $50 \%$ indicating high heterogeneity. The $I$-square values were $71.7 \%, 55.9 \%$ and
65.5 for the overall data of the allelic contrast, homozygote comparison and dominant model, respectively, indicating marked heterogeneities between the studies. Hence, the random-effect models were utilized. However, when subgroup analyses regarding ethnicity and age groups were further conducted, we found loss of heterogeneities in the subgroups regarding Caucasians and childhood AML, respectively.

\section{Meta-analysis results}

The main results of the meta-analysis were listed in Table 3. For the overall data containing 1330 cases and 3688 controls, the pooled ORs for the allelic contrast, homozygote comparison and dominant model were $1.13(95 \% \mathrm{CI}=0.87-1.48), 1.72 \quad(95 \% \mathrm{CI}=0.99-3.01)$ and $1.16(95 \% \mathrm{CI}=0.86-1.55)$, respectively, indicating that

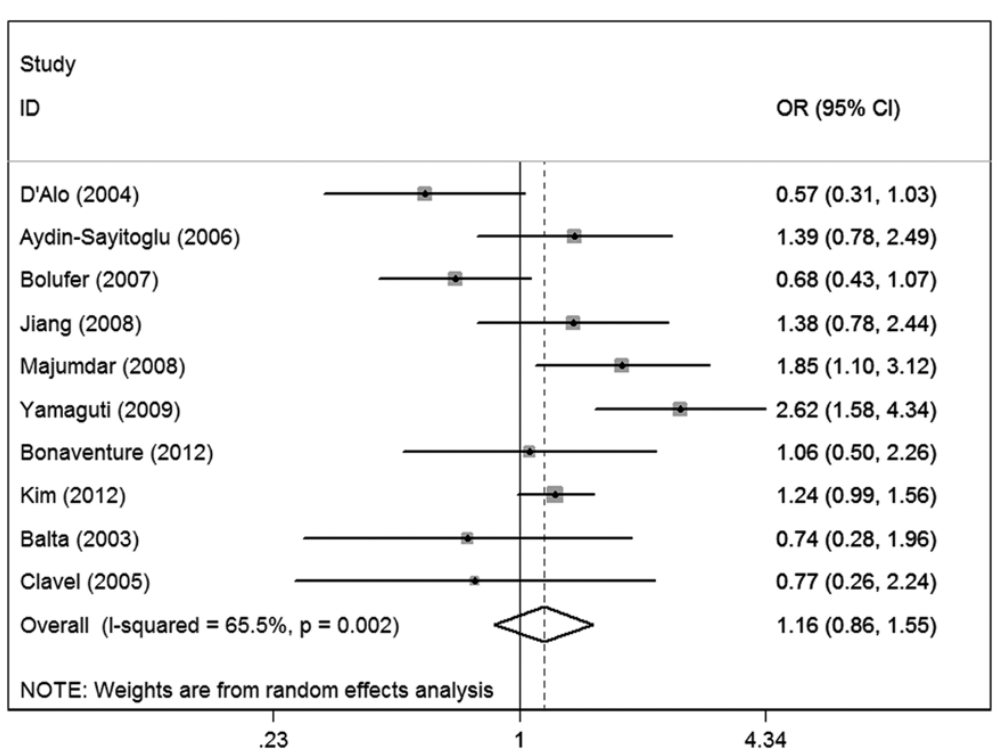

Figure 2 Meta-analysis for the association of acute myeloid leukemia risk with CYP1A1 Mspl polymorphism for the overall data (CC + TC versus TT). 


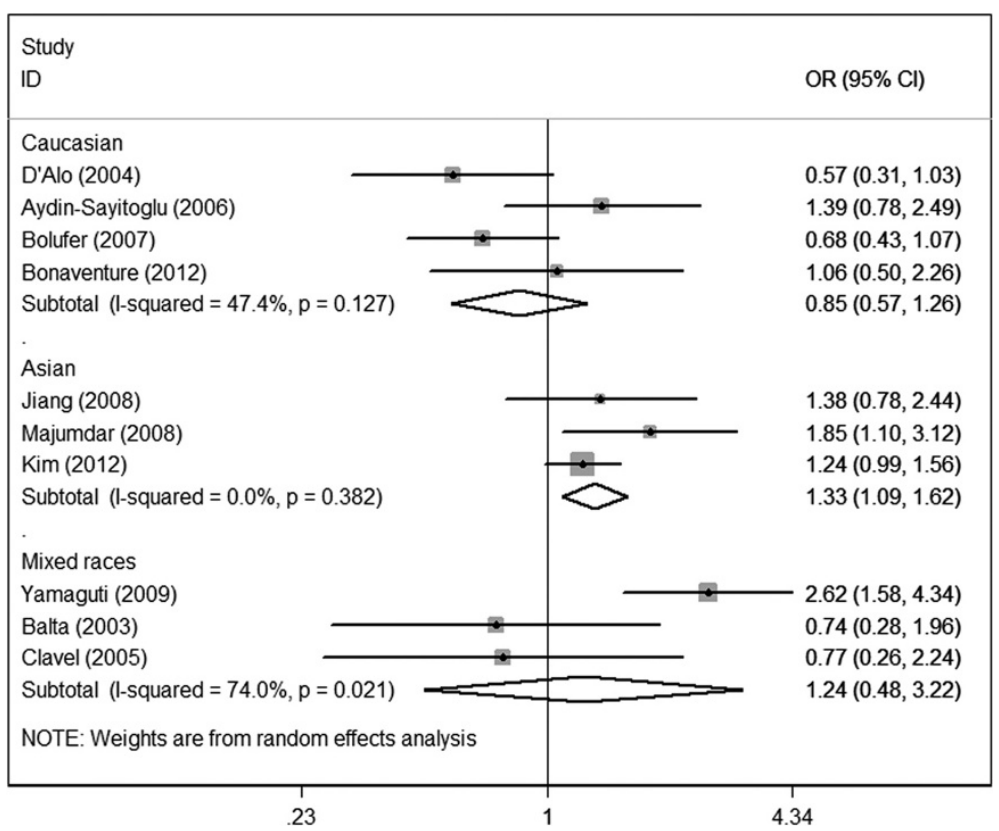

Figure 3 Meta-analysis for the association of acute myeloid leukemia risk with CYP1A1 Mspl polymorphism (CC + TC versus TT; stratified by ethnicity).

CYP1A1 MspI polymorphism might not have a correlation with AML risk (Figure 2).

However, in subgroup analysis according to ethnicity, increased risk was shown among Asians $(\mathrm{OR}=1.33$; $95 \% \mathrm{CI}=1.09-1.62 ; \mathrm{P}=0.382$ for heterogeneity) under the dominant model, but not the allele contrast or homozygote comparison models. No increased risk could be observed among Caucasians or mixed races under the three genetic models. The data indicated that Asians who carry variant $C$ allele might have increased AML risk relative to those who harbor wild type TT alleles. (Figure 3).

In subgroup analyses regarding age groups, no increased risk was found among either the childhood

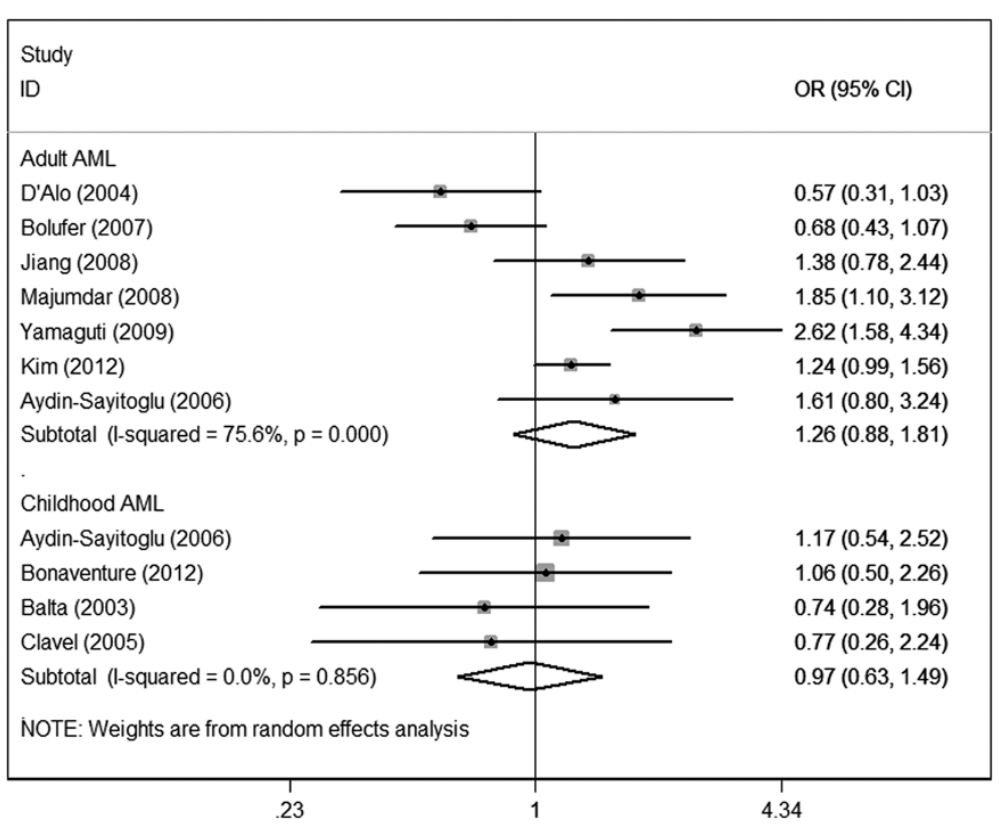

Figure 4 Meta-analysis for the association of acute myeloid leukemia risk with CYP1A1 Mspl polymorphism stratified by age groups (CC + TC versus TT). AML, acute myeloid leukemia. 
AML subgroup or the adult AML subgroup under the three genetic comparisons (Figure 4).

\section{Sensitivity analysis}

When the effect-models were changed, the significance of the overall data for the two comparisons, respectively, was not statistically altered (data not shown). Then, oneway sensitivity analysis [30] was carried out to assess the stability of the meta-analysis. The statistical significance of the results was not changed when any single study was omitted (data not shown), indicating the credibility of the results.

\section{Bias diagnostics}

Funnel plots were created to detect possible publication bias. Then, Egger's linear regression tests were used to assess the symmetries of the plots. The funnel plots appeared to be symmetrical for the overall data (Figure 5a). Moreover, results of the Egger's tests also indicated that the potential publication bias was not evident (Figure $5 \mathrm{~b}$ ) (C allele versus $\mathrm{T}$ allele: $\mathrm{t}=-0.20$, $\mathrm{P}>0.05$; $\mathrm{CC}$ versus TT: $\mathrm{t}=0.66, \mathrm{P}>0.05 ; \mathrm{CC}+\mathrm{TC}$ versus TT: $\mathrm{t}=-0.50, \mathrm{P}>0.05)$.

\section{Discussion}

For the overall data, the results showed that CYP1A1 MspI polymorphism might not have a significant correlation with AML risk. Moreover, in subgroup analyses stratified by ethnicity, the data suggested an excess AML risk among Asians but not Caucasians or mixed races.

Previously, several meta-analyses have been devoted to the association of CYP1A1 MspI polymorphism with other cancer risk. Nevertheless, the results were conflicting. CYP1A1 MspI genetic variations have been

a

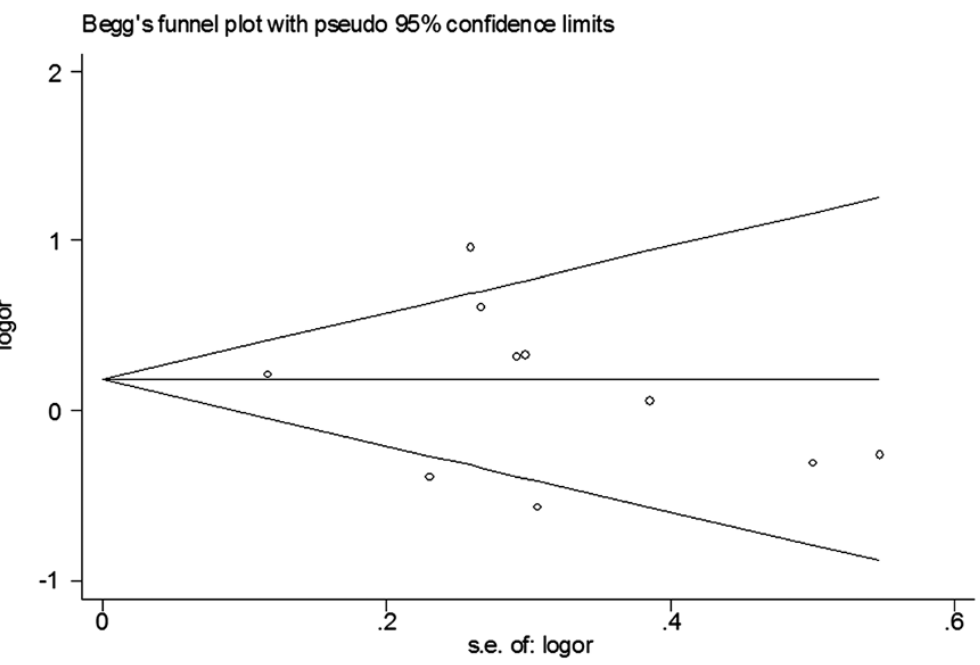

b

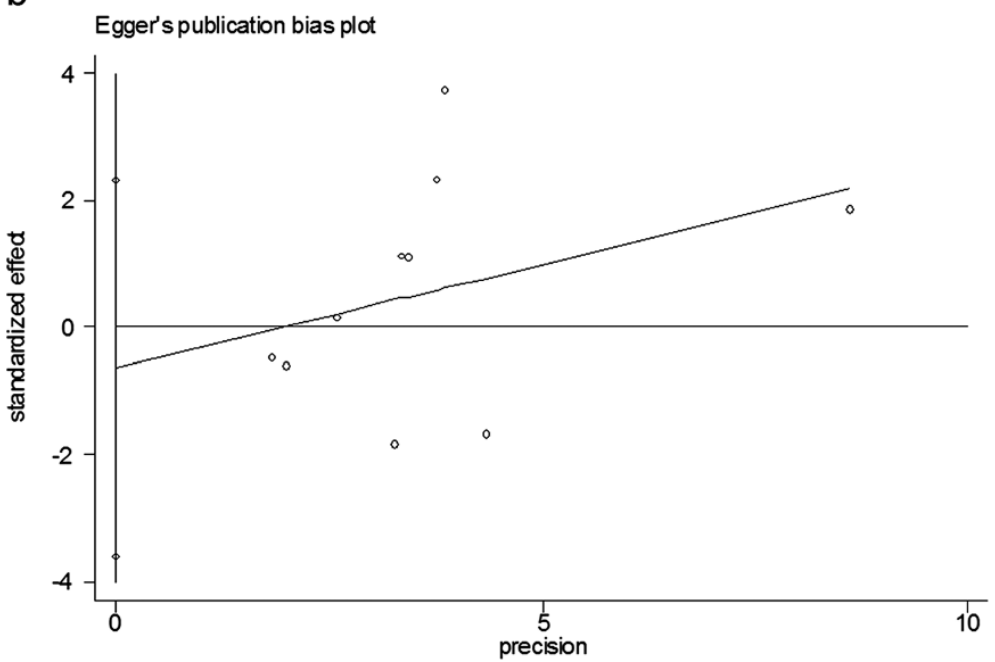

Figure 5 Publication bias tests for the overall data (CC + TC versus TT). (a): Funnel plot; (b) Egger's linear regression test. 
indicated to raise risk for lung cancer, cervical cancer, prostate cancer and laryngeal cancer [31-34]. However, negligible relations between polymorphic CYP1A1 MspI and gastric cancer, colorectal cancer, breast cancer and esophageal cancer risks have been found [35-38]. Therefore, polymorphism of CYP1A1 MspI might play different roles in different cancers.

As for leukemia, a recent meta-analysis by Zhang et al... [39] regarding the relations of CYP1A1 MspI polymorphism with childhood acute leukemia failed to suggest a significant association regarding childhood ANLL (AML), in line with the present study. However, in the study by Zhang et al. [39], only two studies regarding childhood AML were selected [27,28]. Another two important studies that met the inclusion criteria were ignored $[21,25]$. In the present meta-analysis, a total of ten studies concerning childhood AML as well as adult AML were included, which statistically increased power to assess the associations.

In subgroup analysis according to ethnicity, significant increased risk was found among Asians, but not Caucasians and mixed races. Notably, this association could be only observed in the dominant model but not the allele contrast and homozygote comparison models, indicating that Asians who bear variant $\mathrm{C}$ allele of CYP1A1 MspI polymorphism might have an excess AML risk compared with those who carry wild type TT alleles. Possible racial differences in presentation, treatment patterns and survival with respect to AML might exist [40]. The difference might be owing to a possible role of ethnic differences in genetic backgrounds and the environment they lived in. However, the differences might be due to chance because the limited number of included studies and small sample sizes might give rise to insufficient statistical power for detection of a minor effect. Thus, the results should be interpreted with caution because undulated risk estimation might be obtained. Further studies regarding different ethnicities with large sample sizes are needed to clarify this issue.

In the subgroup analysis stratified by age groups, no increased risk was shown among either the childhood AML or the adult AML subgroups. Evidence indicates that the etiologies of childhood AML and adult AML might be different [41]. Moreover, host genetic differences between the two age groups might exist [42]. Therefore, the possible differences regarding CYP1A1 MspI polymorphism between the two age groups should be noted in further investigations. However, the data indicated that the potential difference was not evident in the present meta-analysis.

The overall data were not stratified by source of controls because all studies concerned the population-based controls, except for one study with limited sample sizes [28]. Hospital-based controls might not be always truly representative of the general population. In addition, the population-based controls in several studies were not strictly matched to the cases. Thus, any selection bias might exist. Future studies using proper control participants with strict matching criteria and large sample sizes are important for reducing such selection bias.

In the present meta-analysis, evident between-study heterogeneities for the overall data were observed for the three comparisons, respectively, and thus, the random-effect models were utilized. In the subgroup analyses, loss of heterogeneities was also found in the subgroups regarding Caucasian and childhood AML, respectively. Though we tried to minimize the possibility of encountering heterogeneity problems by conducting a careful search of the literature and using rigorous criteria for data pooling, evident heterogeneities still existed in some of the comparisons. Therefore, heterogeneities might be multifactoral. In addition to ethnicity and age groups, other factors such as gender, source of controls, histological types and prevalence of lifestyle factors might also yield the heterogeneities.

Several limitations should be concerned in the present meta-analysis. First, the primary articles only provided data about Caucasians, Asians and mixed races. Detailed information regarding other ethnicities such as African should be concerned. Second, subgroup analyses regarding gender and other factors such as smoking, drinking and radiation exposure have not been conducted in the present study because relevant information was insufficient in the primary articles. Third, only studies written in English and Chinese were included in this meta-analysis. Any selection bias should be noted. Furthermore, although the metaanalysis in this study is suggestive, high heterogeneity and lack of significant association in any genetic model among Caucasian and Mixed subgroups or age subgroups observed in this study could also originate from the nature of AML as a genetically heterogeneous disease and further assessment on the relationship between CYP1A1 MspI polymorphism and risk of AML subtypes might provide more instructive information. Additionally, gene-gene and gene-environment interactions should also be considered in the further investigations.

In summary, the results of the present meta-analysis suggest that variant $\mathrm{C}$ allele of CYP1A1 MspI polymorphism might have an association with increased AML risk among Asians. Further investigations are needed to confirm the conclusions.

\section{Competing interests}

The authors declare that they have no competing interests.

Authors' contributions

WZand ZC conceived of the study, and carried out the analysis of the literatures and drafted the manuscript. LZ and YW carried out the collection of the literatures. BZ helped with the statistical analysis and manuscript drafting. ZC and WZ conceived of the study, and participated in its design 
and coordination and helped to draft the manuscript. All authors read and approved the final manuscript.

\section{Acknowledgements}

None declared.

\author{
Author details \\ ${ }^{1}$ Institute of Cancer, Xinqiao Hospital, Third Military Medical University, \\ Chongqing, China. ${ }^{2}$ Department of Environmental Hygiene, College of \\ Preventive Medicine, Third Military Medical University, Chongqing, China. \\ ${ }^{3}$ Institute of Respiratory Diseases,Xinqiao Hospital, Third Military Medical \\ University, Chongqing, China.
}

Received: 26 June 2012 Accepted: 13 July 2012

Published: 30 July 2012

\section{References}

1. Ilhan G, Karakus S, Andic N: Risk factors and primary prevention of acute leukemia. Asian Pacific journal of cancer prevention: APJCP 2006, 7:515-517.

2. Yan J, Yin M, Dreyer ZE, Scheurer ME, Kamdar K, Wei Q, Okcu MF: A metaanalysis of MTHFR C677T and A1298C polymorphisms and risk of acute lymphoblastic leukemia in children. Pediatric blood \& cancer 2012, 58:513-518.

3. Ye Z, Song H: Glutathione s-transferase polymorphisms (GSTM1, GSTP1 and GSTT1) and the risk of acute leukaemia: a systematic review and meta-analysis. European journal of cancer (Oxford, England: 1990) 2005, 41:980-989.

4. Wang L, Yin F, Xu X, Hu X, Zhao D: X-Ray Repair Cross-Complementing Group 1 (XRCC1) Genetic Polymorphisms and Risk of Childhood Acute Lymphoblastic Leukemia: A Meta-Analysis. PloS one 2012, 7:e34897.

5. Yu K, Zhang J, Dou C, Gu S, Xie Y, Mao Y, Ji C: Methionine synthase A2756G polymorphism and cancer risk: a meta-analysis. European journal of human genetics: EJHG 2010, 18:370-378.

6. Boffetta P: Biomarkers in cancer epidemiology: an integrative approach. Carcinogenesis 2010, 31:121-126.

7. Guengerich FP, Shimada T: Activation of procarcinogens by human cytochrome P450 enzymes. Mutation research 1998, 400:201-213.

8. Zhou SF, Liu JP, Chowbay B: Polymorphism of human cytochrome P450 enzymes and its clinical impact. Drug metabolism reviews 2009, 41:89-295.

9. Munafo MR, Clark TG, Flint J: Assessing publication bias in genetic association studies: evidence from a recent meta-analysis. Psychiatry research 2004, 129:39-44.

10. Egger M, Davey Smith G, Schneider M, Minder C: Bias in meta-analysis detected by a simple, graphical test. BMJ 1997, 315:629-634.

11. Yang $Y$, Tian $Y$, Jin $X$, Yan $C$, Jiang F, Zhang $Y$, Tang J, Shen $X$ : A case-only study of interactions between metabolic enzyme polymorphisms and industrial pollution in childhood acute leukemia. Environmental toxicology and pharmacology 2009, 28:161-166.

12. Pelloso LA, Da Silva ID, De Souza NC, Yamamoto M, Botelho CA, Chauffaille Mde L: CYP1A1 polymorphisms modify overall survival in acute myeloid leukemia patients. Leukemia \& lymphoma 2007, 48:1211-1215

13. Barragan E, Collado M, Cervera J, Martin G, Bolufer P, Roman J, Sanz MA: The GST deletions and $\mathrm{NQO}^{*} 2$ polymorphism confers interindividual variability of response to treatment in patients with acute myeloid leukemia. Leukemia research 2007, 31:947-953.

14. Voso MT, D'Alo F, Gumiero D, Guidi F, Hohaus S, Leone G: The CYP1A1*2a allele is an independent prognostic factor for acute myeloid leukemia. Haematologica 2005, 90:982-984.

15. Infante-Rivard C, Krajinovic M, Labuda D, Sinnett D: Parental smoking, CYP1A1 genetic polymorphisms and childhood leukemia (Quebec, Canada). Cancer causes \& control: CCC 2000, 11:547-553.

16. Liu QX, Chen HC, Liu XF, Cao YF, Zhang J, Liu J: Study on the relationship between polymorphisms of Cyp1A1, GSTM1, GST1 genes and the susceptibility to acute leukemia in the general population of Hunan province. Zhonghua liu xing bing xue za zhi 2005, 26:975-979.

17. Chen HC, Hu WX, Liu QX, Li WK, Chen FZ, Rao ZZ, Liu XF, Luo YP, Cao YF: Genetic polymorphisms of metabolic enzymes CYP1A1, CYP2D6, GSTM1 and GSTT1 and leukemia susceptibility. European journal of cancer prevention: the official journal of the European Cancer Prevention Organisation (ECP) 2008, 17:251-258.
18. Bolufer P, Collado M, Barragan E, Calasanz MJ, Colomer D, Tormo M, Gonzalez M, Brunet S, Batlle M, Cervera J, Sanz MA: Profile of polymorphisms of drug-metabolising enzymes and the risk of therapyrelated leukaemia. British journal of haematology 2007, 136:590-596.

19. Bolufer P, Collado M, Barragan E, Cervera J, Calasanz MJ, Colomer D, RomanGomez J, Sanz MA: The potential effect of gender in combination with common genetic polymorphisms of drug-metabolizing enzymes on the risk of developing acute leukemia. Haematologica 2007, 92:308-314.

20. Kim HN, Kim NY, Yu L, Tran HT, Kim YK, Lee IK, Shin MH, Park KS, Choi JS, Kim $\mathrm{HJ}$ : Association of GSTT1 polymorphism with acute myeloid leukemia risk is dependent on smoking status. Leukemia \& lymphoma 2012, 53:681-687.

21. Bonaventure A, Goujon-Bellec S, Rudant J, Orsi L, Leverger G, Baruchel A, Bertrand $Y$, Nelken B, Pasquet M, Michel $G$, et al: Maternal smoking during pregnancy, genetic polymorphisms of metabolic enzymes, and childhood acute leukemia: the ESCALE study (SFCE). Cancer causes \& control: CCC 2012, 23:329-345.

22. Yamaguti GG, Lourenco GJ, Costa FF, Lima CS: High risk of 'de novo' acute myeloid leukaemia in individuals with cytochrome P450 A1 (CYP1A1) and $\mathrm{NAD}(\mathrm{P}) \mathrm{H}$ :quinone oxidoreductase 1 (NQO1) gene defects. European journal of haematology 2009, 83:270-272.

23. Majumdar S, Mondal BC, Ghosh M, Dey S, Mukhopadhyay A, Chandra S, Dasgupta UB: Association of cytochrome P450, glutathione S-transferase and $\mathrm{N}$-acetyl transferase 2 gene polymorphisms with incidence of acute myeloid leukemia. European journal of cancer prevention: the official journal of the European Cancer Prevention Organisation (ECP) 2008, 17:125-132.

24. Jiang $L$, Chen M, Qin G: Association between the polymorphisms of cytochrome P4501A1 and glutathione S-transferase M1, T1 Genes and acute myeloid leukemia in Guangxi. Guangxi Medical Journal 2008, 30:464-466.

25. Aydin-Sayitoglu M, Hatirnaz O, Erensoy N, Ozbek U: Role of CYP2D6, CYP1A1, CYP2E1, GSTT1, and GSTM1 genes in the susceptibility to acute leukemias. American journal of hematology 2006, 81:162-170.

26. D'Alo F, Voso MT, Guidi F, Massini G, Scardocci A, Sica S, Pagano L, Hohaus S, Leone G: Polymorphisms of CYP1A1 and glutathione Stransferase and susceptibility to adult acute myeloid leukemia. Haematologica 2004, 89:664-670.

27. Balta G, Yuksek N, Ozyurek E, Ertem U, Hicsonmez G, Altay C, Gurgey A: Characterization of MTHFR, GSTM1, GSTT1, GSTP1, and CYP1A1 genotypes in childhood acute leukemia. American journal of hematology 2003, 73:154-160.

28. Clavel J, Bellec S, Rebouissou S, Menegaux F, Feunteun J, Bonaiti-Pellie C, Baruchel A, Kebaili K, Lambilliotte A, Leverger G, et al: Childhood leukaemia, polymorphisms of metabolism enzyme genes, and interactions with maternal tobacco, coffee and alcohol consumption during pregnancy. European journal of cancer prevention: the official journal of the European Cancer Prevention Organisation (ECP) 2005, 14:531-540.

29. Higgins JP, Thompson SG, Deeks JJ, Altman DG: Measuring inconsistency in meta-analyses. BMJ 2003, 327:557-560.

30. Tobias A: Assessing the influence of a single study in the meta-analysis estimate. Stata Techn Bull 1999, 8:15-17.

31. Zhuo WL, Wang Y, Zhuo XL, Zhu B, Zhu Y, Chen ZT: Polymorphisms of CYP1A1 and GSTM1 and laryngeal cancer risk: evidence-based meta-analyses. Journal of cancer research and clinical oncology 2009, 135:1081-1090.

32. Shaik AP, Jamil K, Das P: CYP1A1 polymorphisms and risk of prostate cancer: a meta-analysis. Urology journal 2009, 6:78-86.

33. Zhan P, Wang Q, Qian Q, Wei SZ, Yu LK: CYP1A1 Mspl and exon7 gene polymorphisms and lung cancer risk: an updated meta-analysis and review. Journal of experimental \& clinical cancer research: CR 2011, 30:99.

34. Sergentanis TN, Economopoulos KP, Choussein S, Vlahos NF: Cytochrome P450 1A1 (CYP1A1) gene polymorphisms and cervical cancer risk: a meta-analysis. Molecular biology reports 2012.

35. Zhuo WL, Zhang YS, Wang Y, Zhuo XL, Zhu B, Cai L, Chen ZT: Association studies of CYP1A1 and GSTM1 polymorphisms with esophageal cancer risk: evidence-based meta-analyses. Archives of medical research 2009, 40:169-179.

36. Sergentanis TN, Economopoulos KP: Four polymorphisms in cytochrome P450 1A1 (CYP1A1) gene and breast cancer risk: a meta-analysis. Breast cancer research and treatment 2010, 122:459-469.

37. Zheng Y, Wang JJ, Sun L, Li HL: Association between CYP1A1 polymorphism and colorectal cancer risk: a meta-analysis. Molecular biology reports 2012, 39:3533-3540. 
38. Guo R, Guo X: Quantitative assessment of the associations between CYP1A1 polymorphisms and gastric cancer risk. Tumour biology. the journal of the International Society for Oncodevelopmental Biology and Medicine 2012.

39. Zhang YD, Tan LN, Zhang XL, Wei HY, Xiong H, Hu Q: Meta-analysis of cytochrome P4501A1 Mspl gene polymorphism and childhood acute leukemia. Biomedical and environmental sciences: BES 2011, 24:683-687.

40. Bierenbaum J, Davidoff AJ, Ning Y, Tidwell ML, Gojo I, Baer MR: Racial differences in presentation, referral and treatment patterns and survival in adult patients with acute myeloid leukemia: a single-institution experience. Leukemia research 2012, 36:140-145.

41. Larfors $\mathrm{G}$, Hallbook $\mathrm{H}$, Simonsson B: Parental age, family size, and offspring's risk of childhood and adult acute leukemia. Cancer epidemiology, biomarkers \& prevention: a publication of the American Association for Cancer Research, cosponsored by the American Society of Preventive Oncology 2012

42. Juhl-Christensen C, Ommen HB, Aggerholm A, Lausen B, Kjeldsen E, Hasle H, Hokland P: Genetic and epigenetic similarities and differences between childhood and adult AML. Peditric blood \& cancer 2012, 58:525-531.

doi:10.1186/1756-9966-31-62

Cite this article as: Zhuo et al.: CYP1A1 Mspl polymorphism and acute myeloid leukemia risk: meta-analyses based on 5018 subjects. Journal of Experimental \& Clinical Cancer Research 2012 31:62.

\section{Submit your next manuscript to BioMed Central and take full advantage of:}

- Convenient online submission

- Thorough peer review

- No space constraints or color figure charges

- Immediate publication on acceptance

- Inclusion in PubMed, CAS, Scopus and Google Scholar

- Research which is freely available for redistribution 